02;06;07

\title{
Возникновение множественных сбоев под действием протонов В статических ОЗУ с технологической нормой $90 \mathrm{~nm}$
}

\author{
() Н.А. Иванов ${ }^{1}$, О.В. Лобанов ${ }^{1}$, В.В. Пашук ${ }^{1}$, М.О. Прыгунов ${ }^{2}$, К.Г. Сизова ${ }^{3,9}$ \\ ${ }^{1}$ Петербургский институт ядерной физики им. Б.П. Константинова, Национальный исследовательский центр \\ „Курчатовский институт“, Гатчина, Ленинградская обл., Россия \\ ${ }^{2} \mathrm{OOO}$ „O2 Световые Системы“, Санкт-Петербург, Россия \\ ${ }^{3}$ ООО „НПЦ „Гранат“, Санкт-Петербург, Россия \\ IE-mail: ksizova@npcgranat.ru
}

Поступило в Редакцию 21 сентября 2018 г.

Исследовано возникновение сбоев в интегральных схемах памяти под действием протонов с энергией $1000 \mathrm{MeV}$. Проведены анализ и обработка экспериментальных данных. Получены результаты, предполагающие наличие множественных сбоев в микросхемах.

DOI: 10.21883/PJTF.2019.01.47150.17534

Уменьшение норм технологических процессов изготовления интегральных схем (ИС) приводит к тому, что в изделиях микроэлектроники наблюдаются радиационные эффекты от отдельных ядерных частиц, в результате которых возникают не только одиночные, но и множественные сбои (МС)[1,2]. В работах [3-5] было показано, что в CMOS- и CCD-матрицах, облученных протонами и нейтронами, под действием продуктов ядерных реакций образуются локальные скопления (кластеры) с линейными размерами до $20 \mu \mathrm{m}$, состоящие из соседних поврежденных пикселей (спайков). Эти результаты указывают на возможность возникновения МС под действием протонов в других типах ИС, имеющих близкие или меньшие размеры элементарной ячейки и/или чувствительной области, чем размер пикселя матрицы. Целью настоящей работы является изучение возможности возникновения МС в ИС памяти с нормой технологического процесса менее $100 \mathrm{~nm}$ под воздействием высокоэнергетических протонов.

Для исследований были выбраны ИС статического OЗУ - память типа SRAM (производитель Cypress) c технологической нормой $90 \mathrm{~nm}$. Два образца этих ИС были облучены на синхроциклотроне ПИЯФ протонами c энергией $1000 \mathrm{MeV}$ до флюенса $10^{11} \mathrm{~cm}^{-2}$ при плотности потока $10^{8} \mathrm{~cm}^{-2} \cdot \mathrm{s}^{-1}$.

Методика исследования выбранных ИС позволяла разделять ошибки чтения и хранения, а также минимизировать возможность возникновения ошибок записи, происходящих в образцах памяти типа SRAM в процессе облучения. До начала воздействия производилась запись опорных значений данных в массив ячеек памяти образцов. После заполнения всего объема памяти заданным шаблоном ИС подвергались облучению, в процессе которого контролировалось состояние каждого байта памяти. При этом над каждой ячейкой выполнялось три операции, первые две из которых заключались в считывании данных и сравнении их с опорными значениями. Если только в одном из двух первых чтений фиксировалась ошибка, то в качестве третьей операции выбиралась также операция „чтение“ и ошибка классифицировалась как сбой в процессе чтения. В случае фиксации ошибок сразу в двух последовательных чтениях производилась перезапись байта с классификацией ошибки как сбоя, произошедшего во время хранения.

Обеспечение выполнения одинакового количества операций, производимого над каждой ячейкой памяти, позволило равномерно распределить время хранения данных в каждом байте. За счет предварительной инициализации образцов до облучения, а также выборочной перезаписи поврежденных ячеек была достигнута минимизация количества выполнений операций записи в процессе воздействия, что дало возможность снизить вероятность их появления и соответственно исключить их из рассмотрения при проведении анализа экспериментальных данных. Помимо фиксации ошибок чтения и хранения в процессе облучения ИС контролировалось возникновение эффектов типа функционального прерывания (single event function interrupt) и тиристорного эффекта (single event latch-up). Для парирования эффектов данных типов была реализована схемотехническая и программно-алгоритмическая защита. В процессе облучения регистрировались время и характер сбоя, а также адрес поврежденного байта.

В процессе облучения в образцах памяти SRAM были обнаружены одиночные сбои, характеризуемые как ошибки хранения. При этом ошибки чтения зафиксированы не были. Обнаруженные одиночные сбои выражались в инверсии одного и того же бита в результате выполнения двукратного чтения выбранного байта информации. В результате исследования за весь сеанс облучения в образцах было обнаружено 16169 и 17414 ошибок хранения информации в различных байтах.

Соответственно среднее сечение одиночных сбоев, рассчитанное по формуле

$$
\Sigma_{e}=n_{e} /\left(F_{p} N_{b i t}\right)
$$

(где $n_{e}-$ количество сбоев, $F_{p}-$ флюенс протонов, $N_{b i t}$ - количество бит в SRAM), составило 

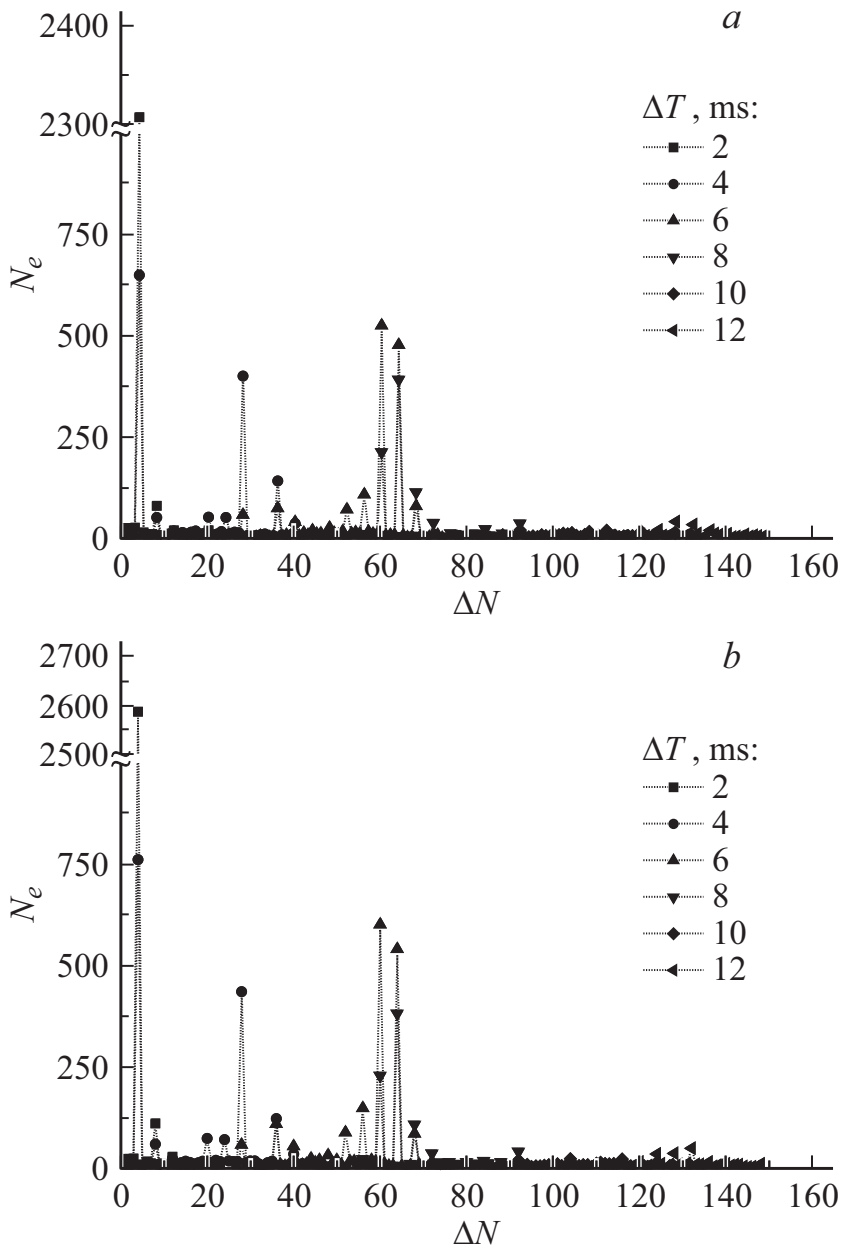

Рис. 1. Распределение числа пар последовательных сбоев $N_{e}$ в зависимости от интервалов в их адресах $\Delta N$ для различных временны́х интервалов $\Delta T$ между ними для образца SRAM № 1 (a) и 2 (b).

$\sim 4 \cdot 10^{-14} \mathrm{~cm}^{-2} \cdot \mathrm{bit}^{-1}$, что хорошо согласуется с данными работы [6] для аналогичных по типу и технологическим нормам изделий.

В пределах каждого цикла чтения всего объема памяти были выявлены сбои, сгруппированные по определенным признакам („кластеры“ сбоев). Во-первых, эти „кластеры“ характеризовались одиночными сбоями, имеющими одинаковый характер: инвертирован один и тот же бит в рассматриваемых байтах. Во-вторых, одиночные сбои в кластерах зафиксированы последовательно с малой разницей во времени регистрации $(\Delta T)$, а также малой и характерно кратной разницей в адресе $(\Delta N)$ ячеек.

По аналогии с возникновением локальных скоплений спайков в CMOS- и CCD-матрицах был проведен анализ полученных экспериментальных данных относительно возможности возникновения МС из числа обнаруженных последовательных одиночных сбоев. На рис. 1 показано распределение количества последовательных сбоев $N_{e}$ в двух образцах SRAM, идущих через определенные временны́е интервалы $\Delta T$, в зависимости от разницы в адресах поврежденных ячеек $\Delta N$. Кратность временны́х интервалов величине $2 \mathrm{~ms}$ между сбоями обусловлена минимальным периодом обработки и выдачи информации опрашивающего ИС устройства. Выбор конкретных значений $\Delta T$ объясняется наибольшей статистикой сбоев в диапазоне $\Delta T$ от 2 до $12 \mathrm{~ms}$. Из рис. 1 видно, что в обоих образцах имеют место ярко выраженные максимумы при $\Delta N=4,28,60,64$, свидетельствующие о том, что сбои разнесены относительно друг друга преимущественно на определенные величины $\Delta N$ и $\Delta T$.

По экспериментальным данным определены распределения количества кластеров $N_{c}$ по количеству одиночных сбоев $n_{e}$, входящих в их состав. При этом в состав кластеров были включены сбои со значениями интервалов времени регистрации $\Delta T \leqslant 8,10$ и $12 \mathrm{~ms}$ и разницей в адресах $\Delta N \leqslant 92,128$ и 148 соответственно. В качестве примера в табл. 1 приведены данные по количеству кластеров $N_{c}$, включающих $n_{e}$ сбоев, для образца SRAM № 1 при $\Delta T \leqslant 8 \mathrm{~ms}$ и $\Delta N \leqslant 92$ байт. Из табл. 1 видно, что количество последовательных сбоев в кластерах может составлять свыше 10. По приблизительным оценкам около $20 \%$ всех сбоев содержатся в $\mathrm{MC}$.

В предположении отсутствия эффекта образования МС временной интервал между возникновением отдельных сбоев является случайным событием, и вероятность того, что временной интервал между двумя последовательными сбоями лежит в интервале от $t$ до $t+\Delta T$, равна [7]:

$$
p(t)=n_{0} e^{-n_{0} t} \Delta T,
$$

где $n_{0} e^{-n_{0} t}-$ плотность распределения вероятностей интервалов $t$ между сбоями, $n_{0}=n_{e} / T_{i r}$ - число сбоев в единицу времени, $T_{i r}$ - продолжительность облучения.

Для образца SRAM № 1 величина $n_{0}$ равна $n_{0}=$ $=n_{e} / T_{i r}=16169 / 985.4=0.0164 \mathrm{~ms}^{-1}$. Соответственно теоретическая зависимость плотности распределения вероятности имеет вид $p_{t h}(t)=0.0164 e^{-0.0164 t}$. Экспериментальные данные по распределению времени между сбоями $\Delta T$ для образца SRAM № 1 приведены в табл. 2 .

Таблица 1. Количество кластеров $N_{c}$ в зависимости от количества входящих в их состав сбоев $n_{e}$ для образца SRAM № 1 при условии $\Delta T \leqslant 8 \mathrm{~ms}$ и $\Delta N \leqslant 92$ байт

\begin{tabular}{c|c}
\hline$n_{e}$ & $N_{c}$ \\
\hline 2 & 695 \\
3 & 331 \\
4 & 124 \\
5 & 62 \\
6 & 42 \\
7 & 20 \\
8 & 9 \\
9 & 8 \\
11 & 4 \\
12 & 4
\end{tabular}


Таблица 2. Распределение сбоев по разнице во времени между сбоями $\Delta T$ для образца SRAM № 1

\begin{tabular}{c|c||c|c}
\hline $\begin{array}{c}\Delta T, \\
\mathrm{~ms}\end{array}$ & $N$ & $\begin{array}{c}\Delta T, \\
\mathrm{~ms}\end{array}$ & $N$ \\
\hline 2 & 2590 & 34 & 161 \\
4 & 1712 & 36 & 134 \\
6 & 1755 & 38 & 169 \\
8 & 1037 & 40 & 142 \\
10 & 321 & 42 & 144 \\
12 & 322 & 44 & 143 \\
14 & 223 & 46 & 156 \\
16 & 184 & 48 & 118 \\
18 & 214 & 50 & 118 \\
20 & 175 & 52 & 119 \\
22 & 171 & 54 & 127 \\
24 & 195 & 56 & 108 \\
26 & 174 & 58 & 119 \\
28 & 173 & 60 & 124 \\
30 & 147 & 62 & 107 \\
32 & 160 & 64 & 126
\end{tabular}

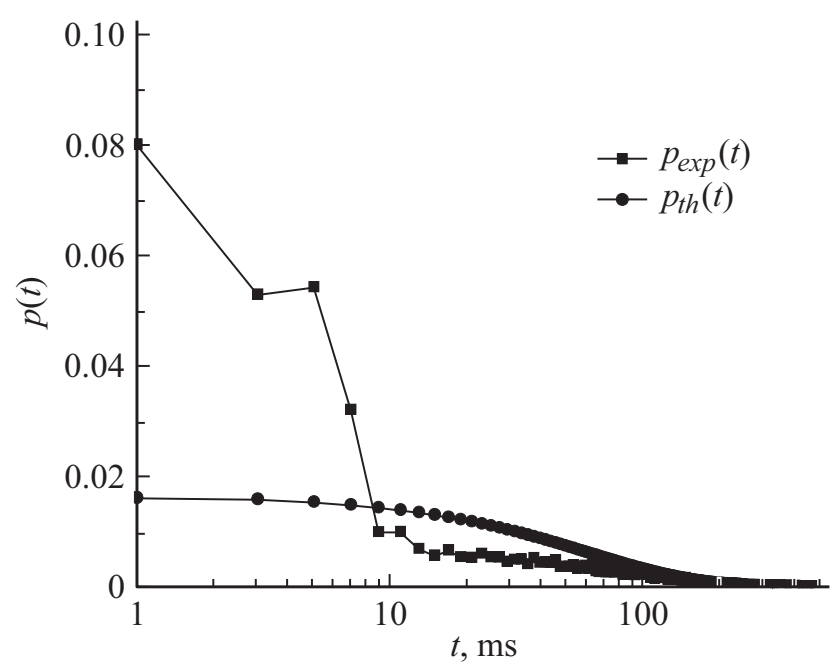

Рис. 2. Сравнение теоретической $p_{t h}(t)$ и экспериментальной $p_{\exp }(t)$ зависимостей вероятностей интервалов времени между сбоями для образца SRAM № 1.

На рис. 2 представлены теоретическая зависимость плотности вероятности интервалов времени между случайными событиями $p_{t h}(t)$ и зависимость плотности вероятности $p_{\text {exp }}(t)$, полученная по экспериментальным данным. Превышение экспериментальной зависимости $p_{e x p}(t)$ над теоретическими значениями $p_{t h}(t)$ означает, что значительная часть сбоев при $\Delta T \leqslant 10 \mathrm{~ms}$ входит в состав МС, т.е они не являются случайными независимыми событиями. Проведенный статистический анализ экспериментальных данных может быть полезен при оценках чувствительности ИС к возникновению МС при отсутствии данных о пространственном распределении адресов ячеек.

\section{Список литературы}

[1] Mavis D.G., Eaton P.H., Sibley M.D., Lacoe R.C., Smith E.J., Avery K.A. // IEEE Transact. Nucl. Sci. 2008. V. 55. N 6. P. 3288-3294.

[2] Зебрев Г.И., Горбунов М.С., Усейнов Р.Г., Озеров А.И., Емельянов В.В., Анашин В.С., Козюков А.С., Земщов К.С., Шередеко Г.С. // Проблемы разработки перспективных микро- и наноэлектронных систем (МЭС). 2014. N 3. C. $167-176$.

[3] Иванов Н.А., Лобанов О.В., Митин Е.В., Пашук В.В., Тверской М.Г. // Письма в ЖТФ. 2013. Т. 39. В. 17. С. 35-43.

[4] Иванов Н.А., Лобанов О.В., Пашук В.В., Прыгунов М.О. // Вопр. атомной науки и техники. 2016. В. 3. С. 30-33.

[5] Иванов Н.А., Лобанов О.В., Пашук В.В., Прыгунов М.О., Сизова К.Г. // Тез. докл. 20-й Всерос. науч.-техн. конф. „Радиационная стойкость электронных систем“ („Стойкость2017“). Лыткарино, 2017. С. 64-65.

[6] Cannon E.H., Cabanas-Holmen M., Wert J., Amort T., Brees R., Koehn J., Meaker B., Normand E. // IEEE Transact. Nucl. Sci. 2010. V. 57. N 6. P. 3493-3499.

[7] Калашников В.И., Козодаев М.С. Детекторы элементарных частиц. М.: Наука, 1966. С. 246-249. 